\title{
A PRODUÇÃO SOCIAL DA IDENTIDADE NO DISCURSO PUBLICI- TÁRIO DA CULINÁRIA PARAIBANA
}

\author{
Maria Regina Baracuhy ${ }^{1}$ \\ Edileide de Souza Godoi²
}

Resumo: Considerando que a Análise do Discurso francesa compreende o sujeito como um ser social, constitutivamente disperso, heterogêneo, que pode ocupar diferentes posições sociais, relacionadas a determinadas formações discursivas (FDs) e ideológicas (FIs), este trabalho tem por objetivo discutir como vêm sendo construídos alguns processos identitários do homem paraibano no discurso culinário que circula em nossa sociedade. Para isso, nosso estudo levará em conta a noção de identidade intrinsecamente ligada à noção de sujeito, isto é, as identidades se constituem em diferentes momentos e lugares, conforme os vários papéis sociais que estamos exercendo. Assim como o sujeito, a identidade também é heterogênea e se insere dentro de formações discursivas específicas, embora atravessadas por outras FDs. Neste trabalho, serão analisados dois anúncios publicitários: um veiculado no folder de propaganda oficial encomendada pela prefeitura de Cabedelo (PB) no mês de outubro de 2005 e o outro se trata da propaganda do rubacão um prato tipicamente paraibano, encomendado pelo governo da Paraíba à revista Engenho da Gastronomia no mês de junho 2005, em que circula o discurso gastronômico paraibano. Pretendemos, com base no referencial teórico da Análise do Discurso francesa, discutir algumas construções identitárias no discurso culinário paraibano.

Palavras-chave: Formação discursiva, Memória, Identidade, Culinária paraibana.

Abstract: Discourse analysis of the French school understands the subject as a social being, dispersed, constitutively heterogeneous, that can occupy different social positions, related to particular discursive and ideological formations. Our post-graduate project aims to discuss the ways in which the culinary discourse that circulates in our society contributes to the construction of the Paraiban people's identity. The study takes into account the notions of identity and subject, as intrinsically connected. Identities are formed in different moments and places, in conformity with various social papers we excerpt. Like the subject, identity too is heterogeneous, inserted inside specific discursive formations, although crossed by others. In the present work, two public announcements are analyzed: one from a folder of official advertising ordered by the local government of Cabedelo (PB) in October 2005, and the other an advertisement for rubacão, a typical Paraiban dish, sent by

1 Professora Adjunta do Programa de Pós-Graduação em Lingüística - PROLING, da Universidade Federal da Paraíba - UFPB. Endereço eletrônico: mrbaracuhy@uol.com.br

2 Mestranda do Programa de Pós-Graduação em Lingüística - PROLING, da Universidade Federal da Paraíba - UFPB. Endereço eletrônico: edileidegodoi@bol.com.br. 
the government of Paraiba to the magazine Engenbo de Gastronomia in June 2005, where there is a circulation of Paraiban gastronomic discourse. We intend, on the basis of the theory of discourse analysis, to argue for the role of Paraiban gastronomic discourse in the construction of identity.

Key words: Discursive formation, Memory, Identity, Paraiba’s gastronomic.

\section{INTRODUÇÃO}

Freqüentemente ouvimos falar de identidade como se fosse algo fixo, imutável. Quando digo "sou paraibano" parece que estou fazendo referência a uma identidade fixa e imutável que se limita em si mesma. Para alguns estudiosos no assunto como Stuart Hall, Tomaz Tadeu da Silva, Kathryn Woodward e outros, a identidade não é algo estável, singular, mas "um processo" construído ao longo dos discursos, práticas e posições sociais, que passa constantemente, por mudanças e transformações.

Mas o que leva pessoas a se identificarem como pertencentes a uma nacionalidade, um grupo ou raça? Como identificar o homem contemporâneo enquanto sujeito social, uma vez que, por conta das mudanças e as transformações efêmeras que o tempo nos proporciona, por meio dos avanços tecnológicos dos meios de comunicação, não há mais uma identidade fixa, imutável, única na sociedade globalizada contemporânea?

Hall (2000) relata que, para pensar a identidade de um sujeito, é necessário inseri-lo dentro de práticas e formações discursivas específicas em diferentes momentos sociais, isto porque é a partir das especificidades próprias de cada grupo ou comunidade que o indivíduo se identifica com seus valores e costumes.

Este trabalho tem como objetivo discutir a identidade do povo paraibano, numa perspectiva discursiva, isto é, pensando o sujeito em um determinado tempo e lugar, onde seu discurso significa, conforme as formações discursivas em que está inserido.

O referencial teórico que embasará nosso trabalho é o da Análise do Discurso francesa, pois essa teoria nos permite analisar a relação sujeito - identidade em uma conjuntura sócio-histórico-ideológica, em que o discurso gastronômico revela o entrecruzamento com outros discursos e, conseqüentemente, com outros sujeitos.

O corpus escolhido para este estudo serão dois anúncios publicitários: um veiculado no folder de propaganda oficial encomendada pela prefeitura de Cabedelo (PB), no mês de outubro de 2005; e outro encomendado pelo governo da Paraíba à revista Engenho da Gastronomia, no mês de junho de 2005. Em ambos circulam o discurso gastronômico paraibano.

Engenho da Gastronomia é uma revista publicada, bimestralmente, no estado de Pernambuco, que circula em todo Nordeste, no Rio de Janeiro e em cinco cida- 
des de Portugal, sendo distribuída em bancas, hotéis, restaurantes. Através de uma parceria com a Infraero, ela é encontrada em locais de desembarques de vôos cuidadosamente escolhidos. Sendo assim, o público-alvo do citado periódico se compõe tanto de turistas regionais, como nacionais e até mesmo internacionais.

O folder da prefeitura de Cabedelo é um encarte, que acompanha o jornal União, sendo publicado mensalmente no estado paraibano, onde é distribuído em bancas de revistas, hotéis, restaurantes e para passageiros de algumas empresas de onibus estaduais. Portanto, destina-se tanto aos turistas que já estão no estado como ao próprio povo paraibano.

Pretendemos discutir como o discurso culinário, apresentado pelas propagandas, exibe traços identitários do povo paraibano. Além disso, este trabalho objetiva compreender as condições que possibilitaram o discurso culinário ser construído dessa maneira e não de outra.

\section{SUJEITO, IDENTIDADE E FORMAÇÃo DISCURSIVA}

De acordo com o dicionário Aurélio, a identidade de um sujeito limita-se à "identidade do eu", o indivíduo sendo o mesmo em diferentes momentos de sua existência. Identidade: "o conjunto de caracteres próprias e exclusivas de uma pessoa; nome idade, estado, profissão, sexo, defeitos físicos e impressões digitais" (HOLANDA, 1990, p. 348).

A Análise do Discurso francesa (AD) reconhece o sujeito como um ser social, inserido em uma conjuntura sócio-histórico-ideológica e vê a identidade ligada às noções de sujeito e alteridade. "Não há consciência de si sem consciência da existência do outro é na diferença entre si e o outro que se constitui o sujeito" (CHARAUDEAU, MAINGUENEAU, 2004, p. 226).

Segundo Marisa Grigolleto, em seu artigo Leitura sobre identidade: contingência negativa e expressão (2006), as identidades são construções sociais situadas culturalmente, que conseqüentemente, têm uma relação inescapável com a alteridade. Assim, para compreender a identidade, faz-se necessário entendê-la em sua relação com a alteridade, construída pela marcação de diferença.

Para alguns estudiosos da identidade como Stuart Hall, mesmo reconhecendo que a identidade é construída pela alteridade, concebe que não há rigidez quanto à oposição na dicotomia "nós/eles"; por exemplo, tanto o paraibano quanto o pernambucano são nordestinos, embora o paraibano esteja inserido em práticas sociais diferentes das do pernambucano. Daí Hall (2003) assumir uma posição que dá ênfase à fluidez da identidade, vendo-a como uma construção moldada conforme as práticas sociais e formações discursivas a que os sujeitos estão submetidos.

Em vista disso, a identidade pode ser enfocada de duas maneiras distintas: a identidade do ser individual, empírico como supõe o dicionário Aurélio; e uma outra dita de "posicionamento", que diz respeito à posição que o sujeito ocupa 
num campo discursivo. Esse tipo de identidade se inscreve dentro de uma formação discursiva e resulta das condições de produção e estratégias inscritas na situação comunicacional. O posicionamento do sujeito influencia na produção dos seus discursos, ou seja, nas escolhas das construções, das palavras, dos gêneros discursivos, na maneira de citar, etc. Para Charaudeau (2004, p. 393), "o posicionamento corresponde à posição que um locutor ocupa em um campo de discussão, aos valores que ele defende (consciente ou inconscientemente) e que caracterizam reciprocamente uma identidade social e ideológica".

Embora possamos nos ver como sendo a mesma pessoa em todas as distintas situações discursivas, não é difícil perceber que nos posicionamos diferentemente em momentos e lugares variados, conforme as diferentes posições sociais que assumimos. Kathryn Woodward (2000, p. 30), defende que "diferentes contextos sociais fazem com que nos envolvemos em diferentes significados sociais".

Para Foucault (2005, p. 105) o sujeito existe sob a forma de dispersão. "Um único e mesmo indivíduo pode ocupar, alternadamente, em uma série de enunciados, diferentes posições e assumir o papel de diferentes sujeitos".

Estudar o sujeito e a identidade pelo viés da $\mathrm{AD}$ francesa significa reconhecer que ambos são construções dinâmicas, cambiantes, pois vão mudando de acordo com a formação discursiva que os determina.

Não podemos falar de sujeito e identidade sem passar pelo que significa uma formação discursiva, pois de acordo Orlandi (2005) "a noção de formação discursiva (FD) permite-nos observar - e qualificar - as diferenças produzidas na textualização do discurso", além do mais é nas FD que se inscreve o sujeito, caracteriza-se pelas regras de aparição de um discurso em determinado tempo e lugar. Trata-se de compreender como os discursos e os sujeitos são socialmente organizados, em um dado momento histórico. Assim, todos os dizeres que circulam na sociedade se inscrevem dentro de uma determinada formação discursiva. Porém, uma formação não é um espaço estruturalmente fechado, homogêneo, ao contrário, esse conceito se define constitutivamente heterogêneo, um entrecruzamento de diferentes discursos que vêm de outro lugar, outro contexto histórico, por outras posições-sujeitos, mas ressignificado sob novas condições de produção.

Foucault em seu livro Arqueologia do saber (2005) propõe o conceito de formação discursiva a partir das formas de "repartição e sistemas de dispersão" dos enunciados. Para ele, buscar a unidade, a singularidade dos enunciados sobre determinado objeto não estaria na continuidade, na linearidade dos objetos, mas na ruptura, na descontinuidade, na transformação, série; "definir um conjunto de enunciados no que ele tem de individual consistiria em descrever a dispersão desses objetos, apreender todos os interstícios que os separam, medir as distâncias que reinam entre eles [...], formular sua lei de repartição" (p. 37). E assim, o teórico em questão (2005, p. 43) define o conceito de formação discursiva: 
No caso em que se puder descrever, entre certo número de enunciados, semelhantes sistema de dispersão, e no caso em que entre os objetos, os tipos de enunciação, os conceitos, as escolhas temáticas, se puder definir uma regularidade (uma ordem, correlações, posições e funcionamentos, transformações), diremos por convenção, que se trata de uma formação discursiva.

Portanto, é a partir de uma formação discursiva que compreendemos o porquê da existência de um enunciado em determinado contexto sócio-histórico e não outro em seu lugar.

Segundo Cleudemar (2007), os objetos, os tipos de enunciação, os conceitos e os temas obedecem a regras de formação que refletem as condições de existência, isto é, os discursos obedecem a regras de aparição em determinada formação discursiva, historicamente marcada.

Enfim, esse conceito é significante na construção da identidade porque nele se encontra o discurso, o sujeito (posições-sujeito), o sentido, e, conseqüentemente, a História e a memória. O conceito de memória também é significativo no que diz respeito à identidade, porque é a partir de uma memória, ou redes de memória que compreendemos certos sentidos, narrativas, sínteses, representações que se cristalizam em nossa cultura, "trata-se de acontecimentos exteriores e anteriores ao texto, e de uma interdiscursividade, refletindo materialidades que intervêm na sua construção" (FERNANDES, 2007, p. 65)

Para Pêcheux, (1999, p. 53) "a memória discursiva seria aquilo que face a um texto que surge como acontecimento a ler, vem restabelecer os "implícitos" (que dizer, mais tecnicamente, os pré-construídos, elementos citados e relatados, discursos transversos, etc.) de que sua leitura necessita".

Discutir a identidade do paraibano, nos textos de propaganda que trazem um discurso culinário, significa analisar, na dispersão dos enunciados gastronômicos, as regularidades que simbolicamente identifica o povo paraibano. Portanto, "descrever um conjunto de enunciados no que ele tem de singular é descrever a dispersão desses sentidos” (GREGOLIN, 2004, p. 90).

Percebemos que, nos textos publicitários que trazem um discurso culinário paraibano, pelo menos, duas formações discursivas são evidentes: uma que carrega marcas discursivas relacionadas à culinária nordestino-paraibana, que tem como público-alvo o turista do Nordeste, e uma outra, que vem destacando os frutos do mar e se direciona ao turista de fora do Nordeste.

Portanto, é compreendendo o discurso culinário, que se materializa nos textos de propaganda como um "conjunto de enunciados, que se apóia em um mesmo sistema de formação" (FOUCAULT, 2005, p. 122) que analisaremos sua função enunciativa, buscando por meio dos "ditos" e "não-ditos", compreender quais as condições para o aparecimento de uma série de signos como acontecimento específico, "suas condições, suas regras de controle, o campo em que ele se realiza" 
(GREGOLIN, 2004, p. 91), porque não há entre o enunciado e sua significação apenas uma relação de ordem estrutural ou semântica, mas uma relação que envolve a materialidade lingüística, o sujeito e seu contexto sócio-histórico-ideológico. Pretendemos também, mostrar as marcas discursivas que causam um efeito de empatia entre os textos de propaganda e o sujeito paraibano.

\section{DESCOBRINDO SUJEITOS, CONSTRUINDO IDENTIDADES}

De acordo com Beth Brait (2005), o discurso é a "manifestação da linguagem em funcionamento", daí analisar a propaganda é estudar um gênero discursivo que manifesta práticas lingüísticas, indiscutivelmente, presentes na vida cotidiana. Mas compreender o discurso da propaganda é enxergá-lo além da superfície textual, é buscar seu sentido na sua não-transparência, nas entrelinhas, nas estratégias de sedução, por meio do jogo entre o verbal e o não verbal, no diálogo com o Outro, isto é, significações atravessadas por outros textos, outros discursos, outras formações discursivas.

Analisar o gênero discursivo propaganda, pelo viés da $\mathrm{AD}$ francesa é compreender que os "enunciados refletem as condições específicas e as finalidades de cada referido campo não só por seu conteúdo (temático) e pelo estilo da linguagem [...], mas acima de tudo por sua construção composicional" (BAKHTIN, 2003, p. 261). É nesse conjunto de regras que funda a unidade de um conjunto que se agrega a dimensão sócio-histórica que constitui o discurso.

Nosso corpus se constitui de textos de propaganda turística culinária, com linguagem verbal e não-verbal, as quais foram escolhidas pelo seu caráter de cunho social, reveladoras de práticas sociais e formações discursivas específicas.

A propaganda constitui-se como produto identificador de práticas sociais, enquanto acontecimento de uma determinada época. Esse tipo de texto é um campo fértil em processos polifônicos, polissêmicos e identitários.

Nossa análise focalizará a relação lingüístico-discursiva com o objetivo de compreender as estratégias utilizadas pelo enunciador que possilibitaram que esses dizeres fossem ditos dessa forma e não de outra, bem como buscar, na sua singularidade, fatos reveladores de uma prática social específica, que constrói sujeitos e revela marcas identitárias.

Esse primeiro texto, formado pelo jogo do verbal como não-verbal, trata-se de uma propaganda turística oficial, encomendada pelo governo do estado, que vem ilustrando um prato "tipicamente" paraibano, o RUBACÃO. A materialidade não-verbal (imagem) une-se a outros enunciados de ordem verbal para constituir sentidos específicos por meio de suas regras de aparição, ou seja, funcionamentos discursivos próprios. 


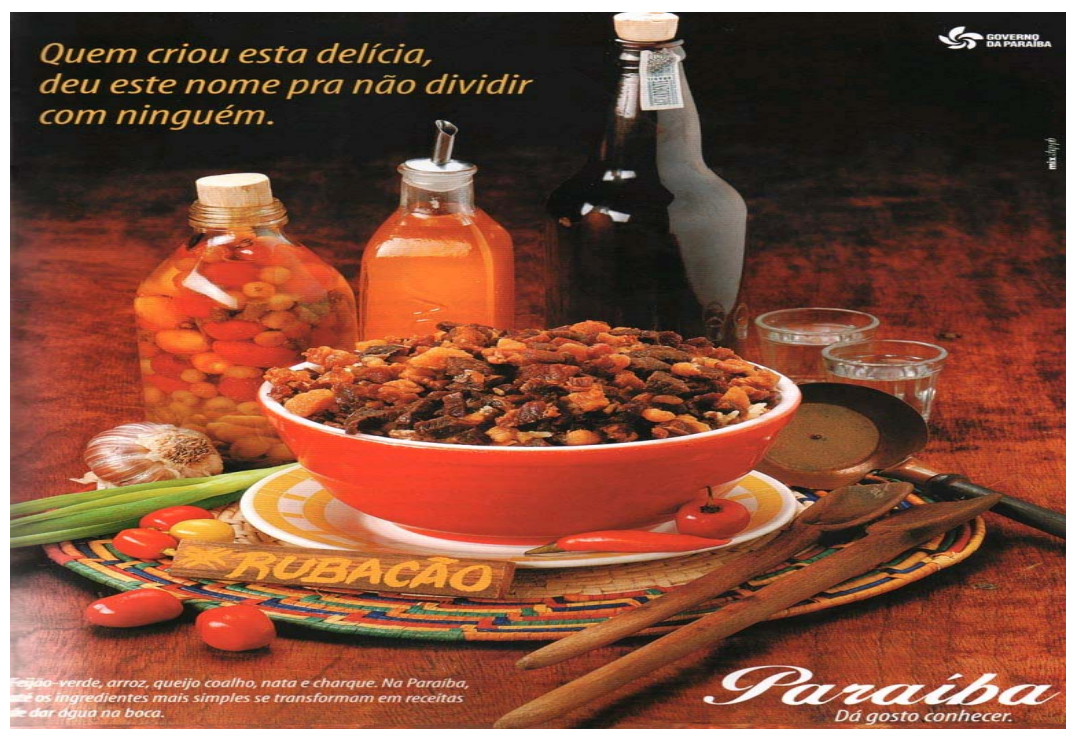

Revista: Engenho da Gastronomia, jun. 2005.

Partindo do princípio que todo discurso está inscrito dentro de uma formação discursiva, que por sua vez é atravessada por outras FDs, entrevemos que na propaganda em análise circulam, pelo menos duas formações discursivas diferentes: uma que se destina ao turista do Nordeste, que reconhece no prato apresentado na propaganda suas particularidades gastronômicas, reforçando assim a identidade nordestina paraibana pelo viés interdiscursivo culinário, e uma outra que tem como destinatário o turista de fora do Nordeste, o qual é convidado a conhecer o desconhecido, o novo. Na propaganda lê-se: "feijão-verde, arroz, queijo coalho, nata e charque. Na Paraíba, os ingredientes mais simples se transformam em receitas de dar água na boca; de um lado, do outro, "Paraíba dá gosto conhecer".

Os jogos enunciativos que a propaganda faz, unindo o verbal ao não verbal (imagético) simultaneamente, atrai tanto o turista do Nordeste quanto o de outras regiões do Brasil e internacional.

Com o objetivo de atrair, persuadir o turista de fora do Nordeste (que ainda não conhece nem o estado nem a culinária paraibana) a vir conhecer e desfrutar de sua deliciosa culinária, a propaganda explora o enunciado: "Paraíba dá gosto conhecer", atribuindo significados diferentes a um mesmo vocábulo, hora usado no sentido denotativo, e hora no sentido figurado, gramaticalmente falando. "Gosto" de sentir prazer em conhecer o estado Paraíba, (sentido figurado, pois só se sente gosto daquilo que se pode comer, saborear) e "gosto" (denotativo) referindo-se ao 
bom paladar da comida paraibana. Esse jogo lingüístico une-se ao texto não verbal, pois o vocábulo "gosto" não teria esse mesmo sentido se a propaganda não usasse como estratégia de sedução a imagem de algo comestível, neste caso, um prato tipicamente paraibano.

Já para atrair o turista nordestino, percebemos que o discurso da propaganda se insere numa formação discursiva que reflete uma formação social própria nordestina, e usa como estratégia de persuasão, um prato característico dessa região, especificamente paraibano, o rubacão o qual vem acompanhado de iguarias também típicas do Nordeste: manteiga da terra, pimenta e cachaça.

Outro fato relevante neste texto é a predominância das cores vermelha e preto, cores muito significativas e sugestivas nesta propaganda, pois são as cores da bandeira da Paraíba, e sendo a bandeira um dos grandes símbolos de representação de um povo, esse conjunto enunciativo verbal e não verbal causa assim um efeito de empatia entre o nordestino (paraibano) e o produto anunciado.

Esse jogo de sedução permite ao homem que vive nessa região, por meio dos interdiscursos (os já ditos, pré-construídos) e da memória coletiva, resgatar valores sócio-culturais peculiares de sua prática social, pois os produtos com os quais o paraibano se depara são produtos plantados ou fabricados na sua própria terra, "com o suor do seu próprio povo", o que os torna mais barato e acessível.

O feijão-verde, a cachaça, a manteiga da terra, o charque, o queijo coalho, a nata representam, simbolicamente, no discurso culinário dentro da propaganda turística, traços identitários do homem nordestino-paraibano, isso ocorre pelo fato desses produtos estarem inseridos a muito mais tempo em sua prática culinária, tornando-se, assim, forte reveladores de práticas e valores ideológicos específicos.

A propaganda “constrói uma 'história do presente', simulando acontecimentos que vêm eivados por signos do passado" (GREGOLIN, 2003, p. 96), por isso mesmo são significativos para o homem paraibano.

Porém, é importante salientar que as marcas discursivas que identificam o paraibano na propaganda são ressignificadas, pois se observarmos a ilustração, percebe-se que o "prato" passou por um "acabamento estético", agregando valores diferentes de outros do estabelecidos em um outro momento histórico. O rubacão, que antes era considerado uma comida rústica, "pesada" símbolo de representação apenas sertaneja, atualmente agrega valores sócio- ideológicos diferentes de uma época passada, sendo, hoje, um produto presente em todas as microrregiões do estado, ofertado o ano inteiro, presente na economia do estado e com forte apelo turístico. O rubacão ganhou outros valores sócio-culturais, que fizeram do prato, símbolo de representação paraibana, pois é reconhecido como comida "tipicamente" paraibana. 
Para de Certeau (1994, p. 212), "os hábitos alimentares constituem um domínio em que a tradição e a inovação têm a mesma importância, em que o presente e o passado se entrelaçam para satisfazer a necessidade do momento".

A propaganda mantém um diálogo com outros discursos. Discursos anteriores e exteriores ao texto, em um outro espaço social, cultural e histórico que existem na memória discursiva, um lugar sócio cultural com formas de trabalho, de lazer, de comer diferentes da atual. Essa memória resgata uma prática social antes vivida apenas pelo homem sertanejo, mas ao ser discursivisada no momento atual, ela ganha novos sentidos. Essa reinserção dessas redes de memória na atualidade ressoa no consumidor paraibano, causando um efeito de identificação.

Segundo Hall (2000), é num suposto e autêntico passado que procuramos validar as identidades, mas que esse passado é ressignificado quando trazidos para o presente se considerarmos que diferentes contextos sociais ou diferentes formações discursivas fazem com que nos envolvamos em diferentes significados sociais. Precisamos considerar diferentes identidades, envolvidas em diferentes ocasiões. Neste contexto específico da propaganda analisada, o sujeito se identifica porque sua posição é de um sujeito que nasceu e "cresceu" na Paraíba, isto é, sua posição enquanto sujeito paraibano ao se deparar com a propaganda, reconhece de imediato, através de uma memória discursiva, uma prática social específica de um grupo ao qual ele se insere. Portanto, as identidades decorrem das posições sociais que o sujeito é obrigado a assumir na sociedade.

Há algo bastante relevante a respeito da identidade, que não podemos deixar passar despercebido: a identidade não pode ser discutida fora de sua relação com a alteridade. O "ser paraibano", por exemplo, não pode ser compreendido fora de um processo de produção simbólica e discursiva em que o "ser paraibano" se signifique por si só. A identidade paraibana carrega em si mesma, o traço do outro, da diferença - "não sou pernambucano", "não sou cearense", etc., portanto, só é possível estabelecer marcas simbólicas que representa o paraibano através do seu discurso culinário, porque existem outros discursos gastronômicos diferentes do seu, ou seja, a representação que se constrói pelo discurso culinário é um processo que se constrói pelo diferencial de cada estado: o rubacão da Paraíba, o acarajé da Bahia, o jerimum de Pernambuco, o caju do Ceará, o maçunin de Alagoas.

Concluímos que o texto em questão, ao se inscrever dentro de uma formação discursiva específica, tem suas próprias regras de aparição, por exemplo, ela não poderia apresentar em sua materialidade visual, imagética, um produto culinário tipicamente nordestino, e, simultaneamente, na materialidade verbal vocábulos fora dessa ordem discursiva.

E por fim, estando este texto dentro das regras do gênero discursivo da propaganda, por mais que traga marcas discursivas que representem simbolicamente o "homem paraibano," agregando valores políticos, econômicos e sociais com A Cor das Letras - UEFS, n. 8, 2007 
os quais ele se identifica, seu objetivo maior será sempre o lucro, ao tentar convencer o consumidor a comprar um produto.

O segundo texto de propaganda, a ser analisado, foi encomendado pela prefeitura de Cabedelo ao jornal União no mês de outubro de 2005, e apresenta em seu texto imagético, a culinária dos frutos do mar, lagosta, camarão, peixe, caranguejo.

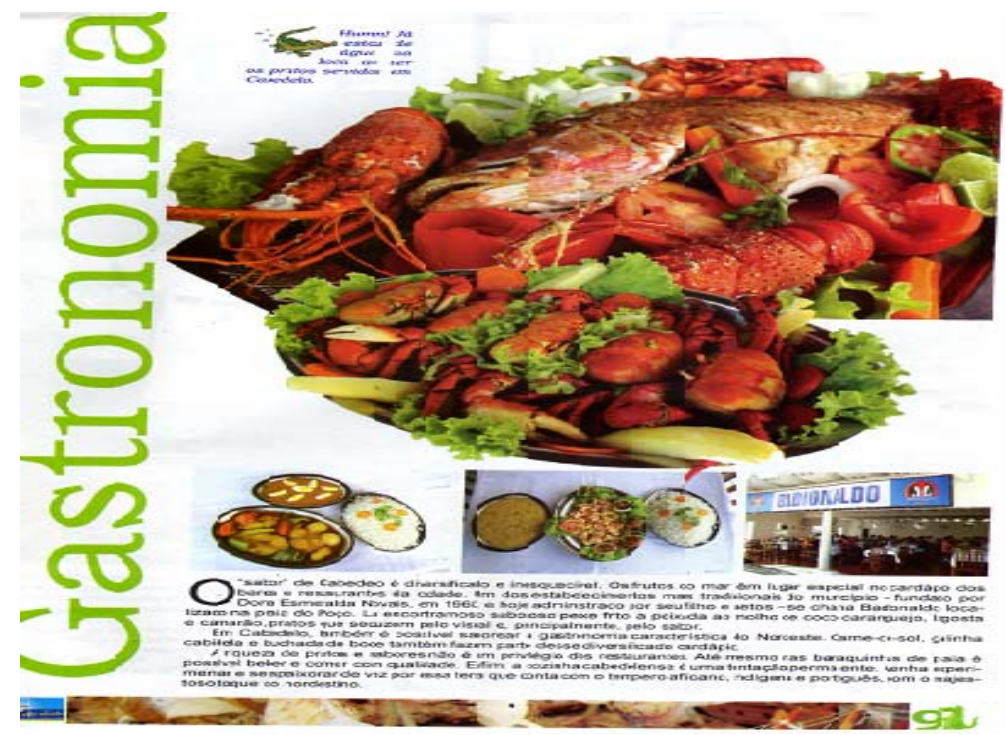

Jornal: União, out. 2005.

Abaixo da imagem, lê-se:

O sabor de Cabedelo é diversificado e inesquecível. Os frutos do mar têm lugar especial no cardápio dos bares e restaurantes da cidade [...]. Lá encontramos o saboroso peixe frito a peixada no molho de coco, caranguejo, lagosta e camarão, pratos que seduzem pelo visual e, principalmente pelo sabor.

Em Cabedelo é possível saborear a gastronomia característica do Nordeste. Carne-de-sol, galinha cabidela e buchada de bode também fazem parte desse diversificado cardápio... Venha experimentar e se apaixonar de vez por essa terra que conta com o tempero africano, indígena e português, com o majestoso toque nordestino (Jornal: União, out. 2005).

Assim como a primeira, essa propaganda apresenta o discurso culinário com objetivo de atrair o turista ao estado paraibano. Embora, em ambos, o discurso em questão seja o culinário, elas significam diferentemente, porque se inscrevem em formações discursivas diferentes. Para Pêcheux (1995, p. 160), "as palavras mudam de sentido segundo as posições mantidas por aqueles que as empregam”. 
Nas propagandas em análise, o discurso culinário se inscreve, em cada uma delas com suas particularidades, conseqüentemente, apresentam sentidos também particulares. A propaganda do rubacão, apresentando em seu texto não verbal, (imagético), o que é muito significativo neste tipo de gênero, uma prática gastronômica de uma determinada região, a nordestina, ou mais especificamente, a paraibana, causando ao consumidor dessa região certa identificação com o produto anunciado.

Já a propaganda em análise tem como destinatário principal o turista de outras regiões do país e o internacional, pois prioriza em sua materialidade lingüística não-verbal, os frutos do mar, uma culinária conhecida quase que mundialmente, especialmente por aqueles que vivem nas cidades litorâneas, tentando convencer não apenas o turista nordestino, mas aqueles indivíduos que estão ou pretendem fazer turismo, pois diferentemente do primeiro texto, esse não usa como estratégia de sedução particularidades gastronômicas de uma determinada região ou estado do país, e sim uma culinária conhecida e apreciada por quase todos os brasileiros e estrangeiros, causando, assim como na propaganda do rubacão, um efeito de empatia entre o alvo e o produto anunciado.

Tanto na primeira propaganda quanto na segunda, o enunciador tenta atrair, persuadir o consumidor, pelo efeito de empatia causado no indivíduo ao se deparar com o produto. Mas é importante frisar que, embora os textos de propagandas aqui analisados tenham usado a mesma estratégia de sedução, persuadir pelo efeito de empatia, a propaganda dos frutos do mar, diferentemente da do rubacão, não causa no consumidor um efeito de identificação. Isso acontece devido esse produto não estar inscrito em uma prática discursiva representativa de um determinado lugar, pois de acordo com Tomaz Tadeu (2000), a identidade é um processo de representação simbólica que se dá dentro de práticas e costumes particulares. $\mathrm{O}$ que nos leva a salientar que o discurso culinário em ambos os textos apresentam sujeitos distintos: o sujeito nordestino paraibano, aquele que come rubacão; e o sujeito que vive e desfruta das delicias do litoral.

Nessa propaganda dos frutos do mar, a materialidade lingüística verbal vem ratificar tanto o enunciador quanto seu destinatário. "venha experimentar e se apaixonar "de vez" por esta terra" o enunciador, o próprio paraibano, aquele que já conhece, já provou e aprovou os frutos do mar, convida, pelo imperativo "venha", o turista a se apaixonar de uma vez por toda por esta terra, deduzindo que ele ainda não se apaixonou de vez, porque ainda não degustou ou experimentou a gastronomia oferecida em Cabedelo, que conta com "o majestoso toque do nordestino". O pronome demonstrativo essa (perto de quem fala) aproxima o enunciador ao vocábulo terra no sentido de terra natal, venha se apaixonar de vez por minha terra, "terra na qual já estou e sou apaixonado". O enunciado "que conta majestoso toque nordestino" reforça o efeito de persuasão no jogo entre o velho e A Cor das Letras - UEFS, n. 8, 2007 
o novo. É o já conhecido, que atrai pelo efeito de empatia, com o novo, que chama atenção pela curiosidade de conhecer o desconhecido, o diferente, "o majestoso toque nordestino". É o velho que se ressignifica no novo. Esse fato torna o prato com características próprias nordestina, embora não seja considerada uma culinária tipicamente dessa região.

No entanto, mesmo a propaganda em questão priorizando em seu texto visual uma formação discursiva voltada par uma prática "gastronômica marítima", que conseqüentemente, se inscreve dentro de uma formação discursiva diferente da do primeiro texto, encontramos em sua materialidade lingüística verbal, enunciados que denunciam uma outra formação discursiva, embora menos evidente, enfatizando uma prática, especificamente nordestino-sertaneja.

Em Cabedelo também é possível saborear a gastronomia característica do nordeste a carne-de-sol, a galinha cabidela e a buchada de bode também fazem parte desse diversificado cardápio.

Esse enunciado, além de apresentar uma outra formação discursiva, ratifica nossa afirmação a respeito de que a culinária apresentada no texto visual se inscreve em uma FD turística não nordestina, quando o enunciador diz que também é possivel saborear a gastronomia característica do Nordeste e apresenta outros pratos como tipicamente nordestino, exclui os frutos do mar da gastronomia característica do Nordeste, mas isso não significa que essa iguaria não seja presente em nossa prática culinária, o que acontece é que diferentemente da gastronomia nordestinosertaneja, esses produtos não carregam em si marcas históricas significativas para cultura dessa região.

De acordo com Wills Leal em seu livro Gastronomia com produto turístico (2006), considerar que alguns produtos sejam símbolos de representação de um grupo não significa dizer que esses produtos não possam ser consumidos por outros grupos

Em ambos os textos, a culinária nordestina é constituída por um discurso pré-estabelecido que exprime por meio de uma memória coletiva, práticas sociais de um povo. Um povo que vive numa terra em que as dificuldades começam com o próprio sentido da palavra "sertão" palavra derivada do latim "desertanum", referente a deserto, terra inóspita, inabitável. Pessoas fortes, sofridas, mas acima de tudo, perseverantes. Um povo que no passado, não muito remoto, sofria com a escassez de políticas sociais reservadas à sua sobrevivência, uma gente que conservava seus alimentos de modo rudimentar, não porque gostavam ou porque isso tornasse a iguaria mais saborosa, mas faziam pela necessidade, para conservar o produto por muitos dias sem que se estragasse; por exemplo, a carne-de-sol, que surgiu no Sertão, onde se usava o sal, uma iguaria barata e acessível, e o sol, algo que não falta no sertão, como matéria-prima para a conservação da carne. No en- 
tanto, essa memória é ressignificada ao ser transportada para o contexto atual, um novo momento histórico, por exemplo, a carne de sol na atualidade é consumida e apreciada por quase todos os paraibanos do litoral ao sertão, independente da classe social. "O prato mais popular da Paraíba é a carne-de-sol (42,8\%)" (LEAL, 2006, p. 155).

Enfim, é na formação discursiva disponibilizada no texto verbal que diz respeito à prática culinária sertaneja que o nordestino paraibano vai reconhecer traços identitários que o representa. A carne-de-sol, a buchada de bode, a galinha a cabidela são pratos apreciadíssimos pelo homem nordestino, que há muito fazem parte de sua gastronomia, marcando, assim, sua singularidade em um espaço sócio histórico específico. Outra singularidade que marca o paraibano, mas, especificamente o de Cabedelo, nessa dispersão enunciativa é a imagem do jacaré, símbolo de representação da cidade de Cabedelo usado nas propagandas turísticas, encomendadas pela prefeitura da cidade.

Para o sujeito paraibano, em particular, esses produtos são símbolo de identificação, pois fazem parte de uma memória discursiva já pré-estabelecida que envolve fatores sociais e econômicos. Woodward (2000, p. 40) diz que:

Se quisermos compreender os significados partilhados que caracterizam os diferentes aspectos da vida social, temos que examinar como eles são classificados simbolicamente. Assim o pão que é comido em casa é visto simplesmente como um elemento da vida cotidiana, mas quando especialmente preparado e repartido na mesa da comunhão, torna-se sagrado, podendo simbolizar o corpo de Cristo.

Conforme vimos, ao examinar um dado sistema de representação, precisamos analisar essas representações numa relação cultural e simbólica, pois um mesmo símbolo vai ter significados distintos, dentro de formações discursivas distintas.

O texto, em que se destacam os frutos do mar, revela práticas discursivas distintas: uma em que está inserido o turista nacional e internacional, e uma outra em que se insere o homem nordestino-paraibano, perceptível na materialidade lingüística verbal.

Concluímos que embora essa propaganda não priorize o discurso da gastronomia nordestina em seu texto imagético, estabelece, em meio à dispersão dos enunciados, regularidades enunciativas que identificam o homem nordestinoparaibano.

\section{Palavras Finais}

Buscar marcas identitárias do homem nordestino-paraibano, através do seu discurso culinário, é tanto desafiador como motivador. Desafiador porque diante das mudanças cada vez mais efêmeras, não há, mais uma identidade fixa na qual o indivíduo possa se reconhecer; motivador porque como afirma de Certeau (1994, 
p. 246), “ a cozinha constitui uma linguagem na qual cada sociedade codifica mensagens que lhe permite significar pelo menos uma parte do que ele é".

Escolhemos trabalhar com o gênero discursivo propaganda porque indiscutivelmente esse tipo de gênero manifesta práticas de nossa vida cotidiana, bem como nos insere em lugares e momentos históricos determinados, nos dando a oportunidade de compreender como os indivíduos e seus discursos são socialmente organizados em lugares e momentos históricos específicos.

\section{REFERÊNCIAS}

BAKHTIN, Mikhail. Estética da criação verbal. Introd. e trad. do russo: Paulo Bezerra. Prefácio à edição francesa: Tzvetan Todorov. 4. ed. São Paulo: Martins Fontes, 2003.

BRAIT, Beth. (Org.). Bakbtin: conceitos chaves. 2. ed. São Paulo: Contexto, 2005.

CHARAUDEAU, Patrick; MAINGUENEAU, Dominique. Dicionário de Análise do Discurso. Coord. da trad.: Fabiana Komesu. São Paulo: Contexto, 2004.

CERTEAU, Michel de. $A$ invenção do cotidiano 2: artes de fazer: Trad.: Ephrim Ferreira Alves. Petrópolis: Vozes, 1994.

CORACINI, Maria José; GRIGOLETTO, Marisa; MAGALHÃES, Izabel. (Org.) Práticas identitárias língua e discurso. São Carlos: Claraluz, 2006.

FERNANDES, Cleudemar Alves. Análise do discurso: reflexões introdutórias. 2. ed. São Carlos: Claraluz, 2007.

FERREIRA, Aurélio Buarque de Holanda. Dicionário Aurélio Escolar de Lingua Portuguesa. São Paulo: Ática, 1989.

FOUCAULT, Michel. A arqueologia do saber. Trad.: Luiz Felipe Beata Neves. 7. ed. Rio de Janeiro: Forense Universitária, 2005.

GREGOLIN, Maria do Rosário. Foucault e Pêcheux na análise do discurso - diálogos \& duelos. São Carlos: Claraluz, 2004.

HALL, Stuart. A identidade cultural na pós-modernidade. Trad.: Tomaz Tadeu da Silva. Guaracira Lopes Louro. 5. ed. Rio de Janeiro: DP\&A, 2001.

JORNAL ENGENHO DA GASTRONOMIA. [Propaganda sem título]. Recife: Governo de Pernambuco, jun. 2005.

JORNAL UNIÃO. [Propaganda sem título]. João Pessoa, out. 2005.

LEAL, Wills; TRIGUEIRO, Carlos. Gastronomia como produto turístico: sabor Nordeste. João Pessoa: Idéia, 2006.

LEAL, Wills. Conquistando o turista pela boca. João Pessoa: Idéia, 2006.

MALDIDIER, Denise. A inquietação do discurso - (re)ler Pếcheux hoje. Trad.: Eni Orlandi. Campinas: Pontes, 2003.

ORLANDI, Eni P. Discurso e Texto formulaşão e circulação dos sentidos. Campinas, 2005.

PÊCHEUX, Michel. Semântica e discurso. Campinas: Ed. da UNICAMP, 1995.

SILVA, Tomaz Tadeu; HALL, Stuart; WOODWARD, Kathryn. (Org). Identidade e diferenca: a perspectiva dos estudos culturais. Petrópolis: Vozes, 2000. 